\title{
Extended exposure to symbolic matching-to-sample: A preliminary analysis
}

\author{
GERALD D. LACHTER and RENEE F. SOLOMON \\ C. W. Post College of Long Island University, Brookville, New York \\ and Harvard University, Cambridge Massachusetts
}

\begin{abstract}
Two pigeons were exposed to a symbolic matching-to-sample procedure in which left side-key responses were reinforced if two sequentially presented center-key stimuli were identical, while right side-key responses were reinforced if the stimuli were different. Five stimulus pairs were used: color (red-green, blue-yellow), shape (circle-triangle, square-plus), and line (horizontalvertical). Subjects were initially exposed to only one stimulus pair, following which they were exposed to the remaining pairs with the order of exposure varying across subjects. The data reveal some transfer across stimulus sets, but provide only equivocal evidence for concept formation.
\end{abstract}

Within the animal learning literature, one procedure used to study concept formation has been matching-to-sample (see Carter \& Werner, 1978, for a review). In this procedure, reinforcement is dependent upon a pigeon's pecking a side key containing a stimulus that is, in some physical way, identical to the stimulus displayed on the center key. Although there are a number of variations of the basic matching (or oddity) paradigm, correct side-key responses depend upon a relationship between the stimulus displayed on the center key and the stimuli displayed on the side keys. When animals are exposed to matching-to-sample (or to some variant) and then tested following this initial acquisition, the results do not unequivocally support the conclusion that a concept has been formed.

As Carter and Werner (1978) have pointed out, a number of procedural difficulties have potentially confounded the interpretation of some of the results obtained using this procedure. However, Zentall, Edwards, and Hogan (1983) conducted a series of studies that seem to support the notion that pigeons are capable of forming concepts. At the same time, they addressed the problems pointed out by Carter and Werner. Zentall, Edwards, and Hogan used a basic testing procedure in which pigeons were exposed to a novel matching (or oddity) problem following prior acquisition of either matching or oddity. The birds were divided into two groups: in one (nonshifted), the procedural requirements for the subjects remained the same; in the other (shifted), the procedural requirements were changed so that a matching problem was followed by an oddity problem. Comparisons of the performances of these groups in transfer tests indicated a superiority of the nonshifted subjects across all of the problem sets. The magnitude of the transfer effects obtained, however, did not equal the criterion performances typical of humans or other primates (Premack, 1976). Similar differences

Correspondence should be addressed to the authors at the Psychology Department, C. W. Post College of Long Island University, Brookville, NY 11548 . in the acquisition of same/different concepts between pigeons and monkeys have also been reported using a serial probe recognition task (Wright, Santiago, Urcuioli, \& Sands, 1983).

Increases in the magnitude of these transfer effects were found by Zentall and Hogan (1978), using negative instances as part of the basic training procedure. Negative instances refer to trials, in which neither comparison is correct, and require the subject to withhold the response. It seems logical to assume that negative instances enhance concept formation by better defining the boundaries of the concept class.

The present experiment sought to determine if concept formation would be enhanced if a within-session procedure that reinforced both correct same responses and correct different responses was employed.

\section{METHOD}

\section{Subjects}

The subjects were two experimentally naive White Carneaux hen pigeons, 6-8 years old at the start of experimentation. They were maintained and trained at $80 \%( \pm 15 \mathrm{gm})$ of their free-feeding weights.

\begin{abstract}
Apparatus
The experimental station consisted of a standard Lehigh Valley Electronics three key pigeon chamber. All three keys were used, and each required a force of approximately $0.25 \mathrm{~N}$ to operate the keyswitch. The stimuli presented on the center key consisted of a red, green, blue, or yellow field, an outline of a white circle, triangle, or square on a black background, and a white horizontal line, vertical line, or a plus sign on a black background. The side keys were illuminated with white light. All stimuli were produced by IEE $12-\mathrm{V}$ inline stimulus projectors. Reinforcement consisted of 2-sec access to a lighted hopper of mixed grain. Ventilation was provided by an exhaust fan, which, in combination with $80 \mathrm{~dB}$ of white noise, provided sound masking.

Procedure

Following shaping of the keypeck response, the subjects were exposed to a symbolic matching-to-sample procedure. A trial began with the illumination of the center key. One peck to this key darkened it for $0.5 \mathrm{sec}$ and produced a second stimulus. One peck to the second stimulus darkened the center key and illuminated both side keys with white light. A peck to the left side key produced reinforcement if the members of
\end{abstract}


the preceding stimulus pair were the same (e.g., red-red); a peck to the right side key produced reinforcement if the members of this pair were different (e.g., red-green). Incorrect responses-left key pecks following a different pair or right key pecks following a same pairproduced a 20 -sec intertrial interval during which the chamber was darkened. This intertrial interval also followed each delivery of reinforcement. A correction procedure was employed in which a given stimulus pair continued to be presented until a trial terminated with reinforcement. Within each session, 128 trials occurred. Each stimulus pair was presented in quasirandom order with the restriction that no stimulus pair occurred more than four times in succession; in each session, each stimulus pair was presented an equal number of times. For Subject 1, the stimulus sets consisted of red-green (Set 1), vertical-horizontal (Set 2), plus-square (Set 3), and blue-yellow (Set 4); for subject 2, the stimulus sets were vertical-horizontal (Set 1), red-green (Set 2 ), circletriangle (Set 3), plus-square (Set 4), and blue-yellow (Set 5). Each stimulus set was presented until a criterion of $80 \%$ correct was achieved for two consecutive 5-session blocks, or until 250 sessions had occurred.

\section{RESULTS}

The percentages of correct responses across each of the stimulus sets were the data of primary interest (shown for each subject in Figures 1 and 2).

Subject 1 was exposed to four stimulus sets: the first and fourth were the color sets, and the second and third were the line and shape sets, respectively. Acquisition to the required criterion was reached for Set 1 following 250 sessions of exposure, although the data are notable for their variability. Exposure to Sets 2 and 3 produced different outcomes. There was no evidence of either acquisition or transfer over the course of exposure. Accuracy following 250 sessions of exposure was essentially the same as was seen during the initial stages. However, acquisition was achieved on Set 4 , the second color set, in fewer than 250 sessions, showing less variability than that seen for Set 1 .
The data obtained with Subject 2 are clearer. Exposure to the initial stimulus set (line) produced acquisition after 250 sessions of exposure. Subsequent stimulus sets showed more rapid acquisition, with the exception of Set 3 (Shape 1). Although the required criterion was not reached for this set, subsequent exposure to the second shape set (Set 4) showed a pattern of acquisition, indicating that some transfer had occurred. Notice that the performance on this set begins at a higher point than that seen for any of the other sets. This indicates that there was, at least, some transfer from the previous shape set. Similarly, the shift from Set 1 to Set 2 produced relatively rapid acquisition, indicating some potential transfer from the line stimuli to the color stimuli. Less transfer was seen from Set 4 to Set 5, the second shape set and the second color set, indicating that the magnitude of the transfer effect is in part a function of the physical stimuli used.

\section{DISCUSSION}

The present data indicate that pigeons are capable of mastering, to some degree, the same/different task, but that it is extremely difficult. Edwards, Jagielo, and Zentall (1983) reported that a simultaneous same/different task was difficult for pigeons to master if all four stimulus conditions were used. Removal of one of the different configurations made learning of the task quite rapid. This effect might demonstrate that absolute, rather than relative, stimulus values are responsible for accurate responding, since the elimination of one of the different sequences would reduce the number of rules necessary to solve the problem effectively. However, if the same-different concept were being employed, a reduction in the sequences should not have an appreciable effect. For that reason, the procedure employed in the present investigation maintained the symmetry of the same and different tasks. Since it is possible that some rule other than a same-different concept might be utilized, it was felt that all stimulus combinations should be employed in order to prevent any potential bias. Lending further support to this approach are the data obtained by Fetterman (1987), who utilized a sequential same/different task for stimulus duration. The data indicate that

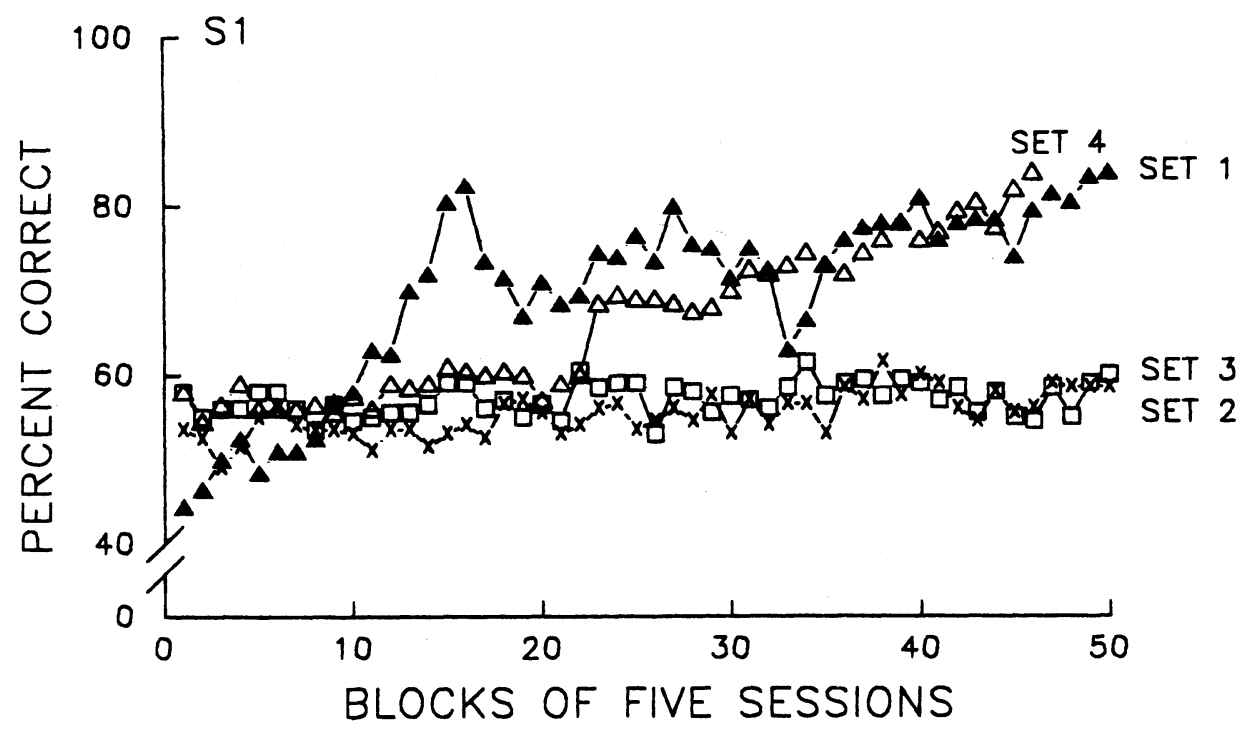

Figure 1. Percent correct responding for Subject 1 as a function of five session blocks of exposure to the various stimulus sets. Note the break in the vertical axis. 


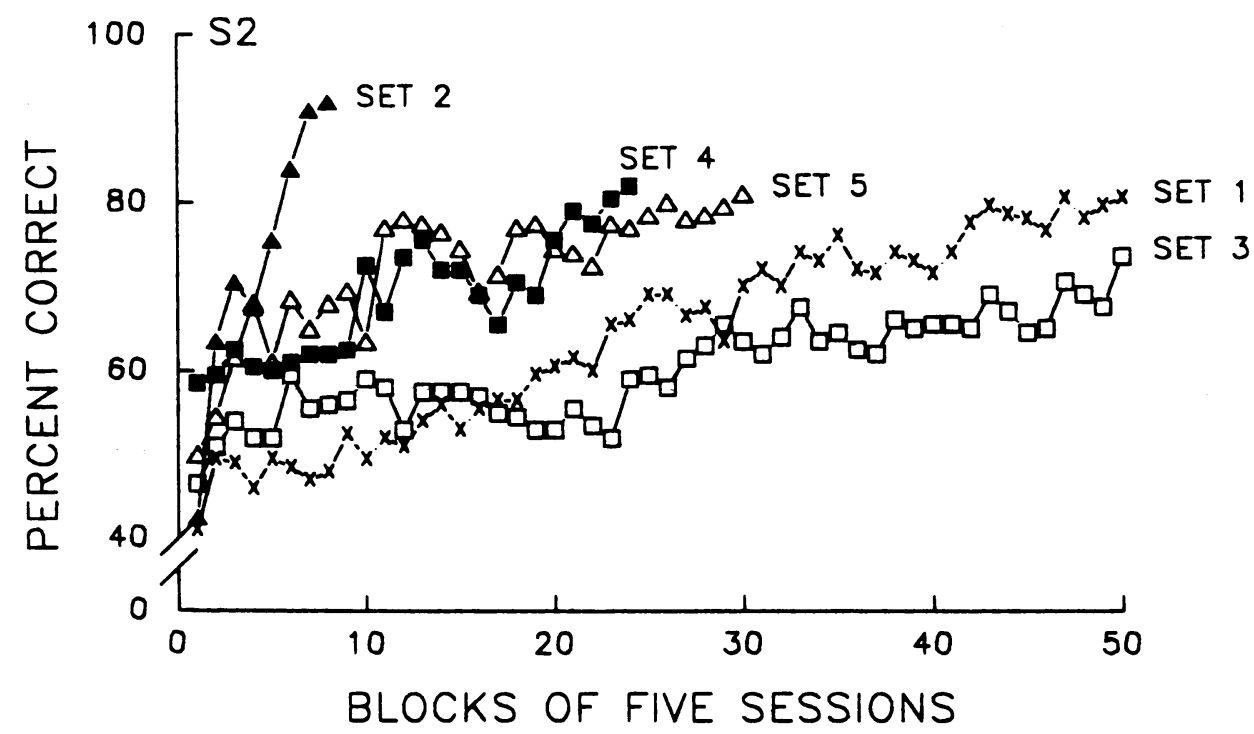

Figure 2. Percent correct responding for Subject 2 as a function of five session blocks of exposure to the various stimulus sets. Note the break in the vertical axis.

pigeons are more accurate on a lesser/greater comparison than on a same/different one. Furthermore, the temporal same/different task was much more difficult, and control by absolute as well as relative stimulus values was observed to occur.

D'Amato, Salmon, and Colombo (1985) have made a case for viewing possession of an identity concept not in an all-or-none fashion, but in terms of its development. In many cases, data obtained with pigeons have, at best, been equivocal. This can be said about the present data, which show some transfer, but only across certain sets. Clearly, other rules exist that would allow pigeons to solve these problems. The present data, as well as the data discussed previously (Edwards, Jagielo, \& Zentall, 1983; Fetterman, 1987), indicate that both the relative and absolute values of stimuli contribute to the pigeons' ability to solve same/ different problems accurately.

\section{REFERENCES}

Carter, D. E., \& Werner, T. J. (1978). Complex learning and information processing by pigeons: A critical analysis. Journal of the Experimental Analysis of Behavior, 29, 565-601.

D’Amato, M. R., Solomon, D. P., \& Colombo, M. (1985). Extent and limit of the matching concept in monkeys (Cebus apella). Journal of Experimental Psychology: Animal Behavior Processes, 11, 35-51.
Edwards, C. A., Jagielo, J. A., \& Zentall, T. R. (1983). "Same/different" symbol use by pigeons. Animal Learning \& Behavior, 11, 349-355.

Fetterman, J. G. (1987). Same-different comparison of duration. Animal Learning \& Behavior, 15, 403-411.

PremaCK, D. (1976). Intelligence in ape and man. Hillsdale, NJ: Erlbaum.

Wright, A. A., Santiago, H. C., Urcuioli, P. J., \& Sands, S. F. (1983). Monkey and pigeon acquisition of same/different concept using pictorial stimuli. In M. L. Commons, R. J. Herrnstein, \& A. R. Wagner (Eds.), Quantitative analyses of behavior: Volume IV. Discrimination processes (pp. 295-317). Cambridge, MA: Ballinger.

Zentall, T. R., Edwards, C. A., \& Hogan, D. E. (1983). Pigeons' use of identity. In M. L. Commons, R. J. Herrnstein, \& A. R. Wagner (Eds.), Quantitative analyses of behavior: Volume IV. Discrimination processes (pp. 273-293). Cambridge, MA: Ballinger.

Zentall, T. R. \& HogAN, D. E. (1978). Same/different concept learning in the pigeon: The effect of negative instances and prior adaptation to transfer stimuli. Journal of the Experimental Analysis of Behavior, 30, 177-186.

(Manuscript received April 23, 1993.) 